\title{
Systemic endotheliomatosis: a case report
}

\author{
J. MADARA, J. SHANE, AND M. SCARLATO \\ From the Department of Pathology, Allentown and Sacred Heart Hospital Center, Allentown, Pa, USA
}

SYNOPSIS A 48-year-old Caucasian man was found to have a rare neoplastic process of vascular endothelial origin. The clinical presentation was that of plum-coloured cutaneous plaques of the lower extremities. The histopathology, natural history, and treatment of this case are discussed and compared with previously reported cases. It is suggested that this disease entity represents a malignant state with systemic involvement and a poor prognosis.

In September 1970, a 48-year-old Caucasian man in apparently good health noticed multiple, elevated, faintly purple cutaneous plaques measuring $1-3 \mathrm{~cm}$ in diameter appearing on the anterior and posterior tibial surfaces bilaterally. Several had a zone of central pallor. From this time until December 1970, when the patient was hospitalized for evaluation, the lesions progressed through three additional morphological stages. The initial lesions lost the zone of central pallor and developed into homogeneous plum-coloured plaques and subsequently into areas of vascular engorgement with a spoke-wheel pattern (figs 1-3). Finally, lesions of a firm, tender, pale, and occasionally pruritic nature evolved.

One year previously, this patient had had a right thoracotomy for excision of a $2.5 \mathrm{~cm}$ spherical

Received for publication 7 January 1975. middle lobe lesion which microscopically was entirely composed of fibrous tissue. Eight months before the current admission the patient had two $5 \mathrm{~cm}$ erythematous cutaneous lesions of the right deltoid region. Medical attention was not sought, and these lesions spontaneously disappeared over a period of two weeks.

On physical examination the patient appeared well developed and in good physical condition. Multifocal, slightly movable, cutaneous plaques were present on the torso and lower extremities. All morphological stages of the lesions were apparent (figs 1-3). The patient denied significant loss of weight or appetite. The only other abnormal findings were those of questionable hepatic enlargement and right inguinal lymphadenopathy.

Apart from the described lesions no other skin abnormalities were present. At this time a neoplastic process was considered, possibly of the Kaposi

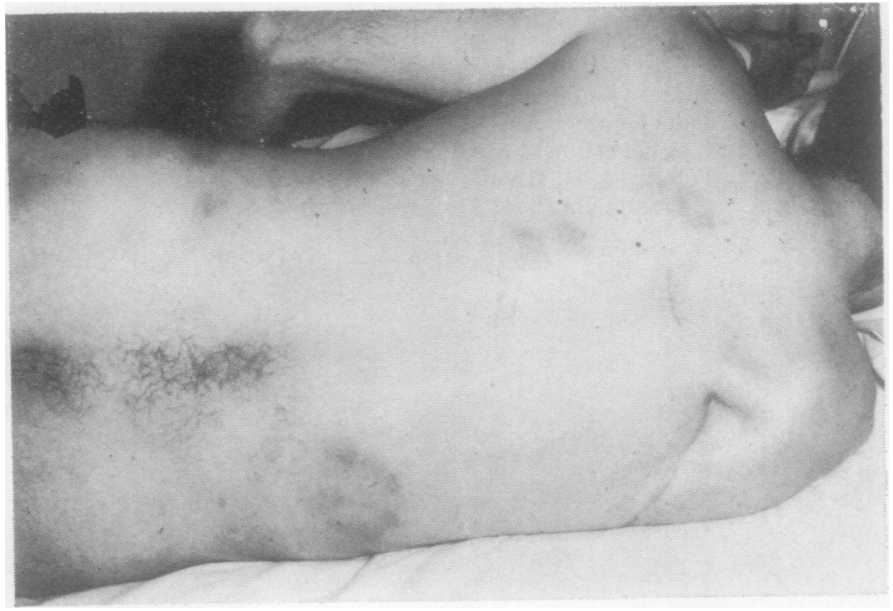

Fig 1 Plum-coloured plaques of trunk and buttock, ranging from 2 to $8 \mathrm{~cm}$. 


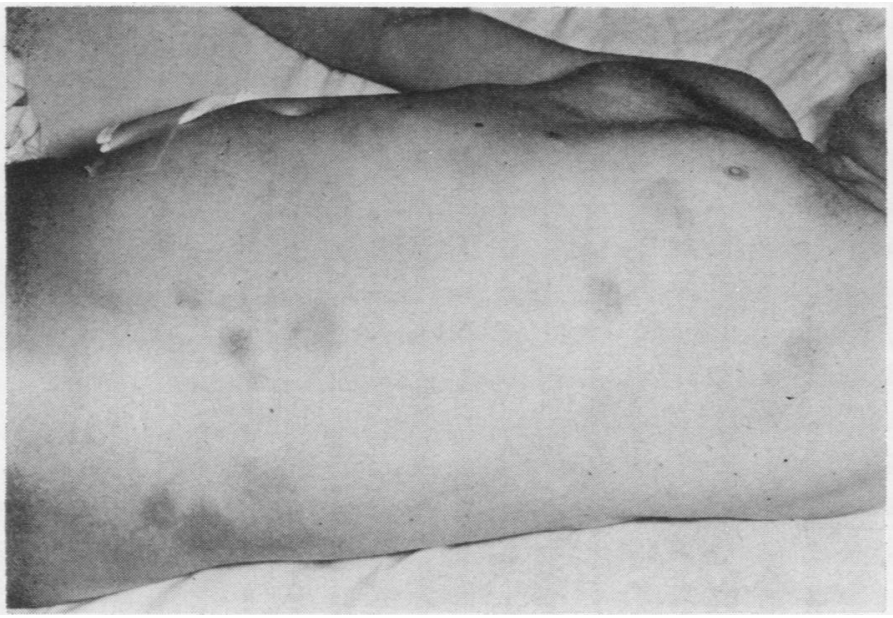

Fig 2 Lesions of same description over lateral chest wall and trunk.

sarcoma variety. One examiner raised the question of an unusual presentation of mycosis fungoides.

Radiographic examination, including chest radiograph, abdominal film, and a liver scan, was within normal limits. Repeat lactate dehydrogenase values were elevated within the $700-750$ unit range $(N=$ 100-225 units). The eosinophil count repeatedly

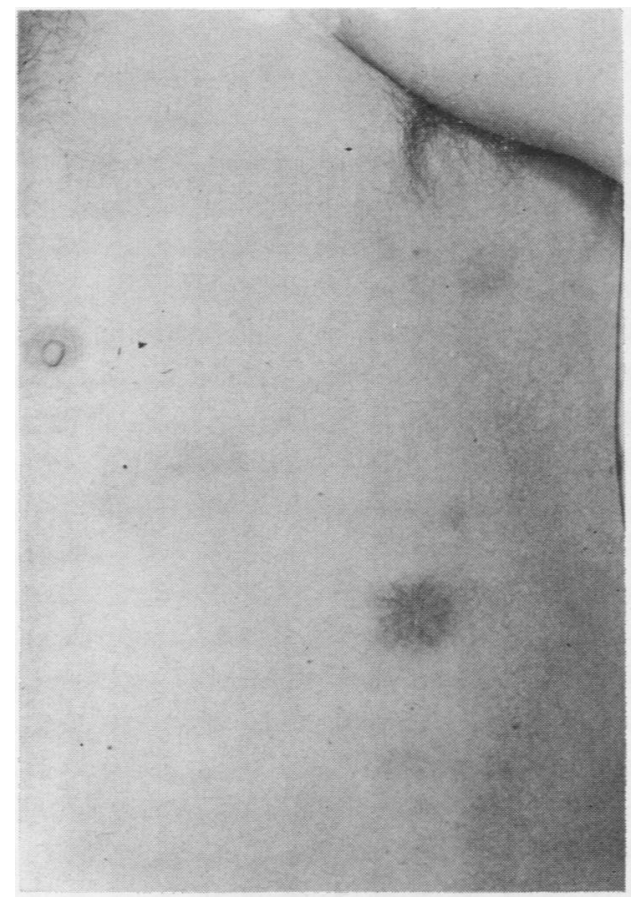

Fig 3 Close-up of lesions in varying stages of development: note the mature lesion with vascular engorgement and the developing lesion with an area of central pallor. ranged from $1260 / \mathrm{mm}^{3}$ to $2360 / \mathrm{mm}^{3}$ although one taken a year previously had not been elevated. The patient had no allergies and was on no medication. The bone marrow was hypocellular. Further laboratory evaluations, including haematological surveys, lupus erythematosus preparations, urinalysis, coagulation profiles, protein electrophoresis, blood chemistries, and thyroid function tests, gave normal results.

Several surgical wedge biopsies of the lesions were examined microscopically, and an intense dermal and subdermal proliferation of capillaries arranged in nests with numerous haphazard anastomoses was found (figs 4-9). These capillary aggregates were separated by uninvolved subcutaneous tissue. The individual capillaries were joined by swollen and atypical endothelial cells which were actively proliferating and shedding into the lumina, many of which were completely filled by these bizarre cells. The nuclei of these atypical cells were large $(>17 \mu)$, vesicular, and pleomorphic with prominent nucleoli and irregular margination of chromatin. The cytoplasm was pale and homogenous. Many capillaries contained partially organized fibrin thrombi. The

\begin{tabular}{ll}
\hline Stain & $\begin{array}{l}\text { Atypical Endothelial Cell } \\
\text { Reactivity }\end{array}$ \\
\hline Alkaline phosphatase & Normal \\
Acid phosphatase & Moderately intense \\
B Glucuronidase & Mild-moderate \\
Dopa oxidase & Non reactive \\
Indoxyl acetate & Weak to moderate \\
Oil-red O & Negative \\
Leucyl aminopeptidase & Intense \\
Adenosine triphosphatase & Intense \\
Succinodehydrogenase & Moderate \\
G-6-Phosphatase dehydrogenase & Negative \\
\hline
\end{tabular}

Table Results of enzyme histochemistry 


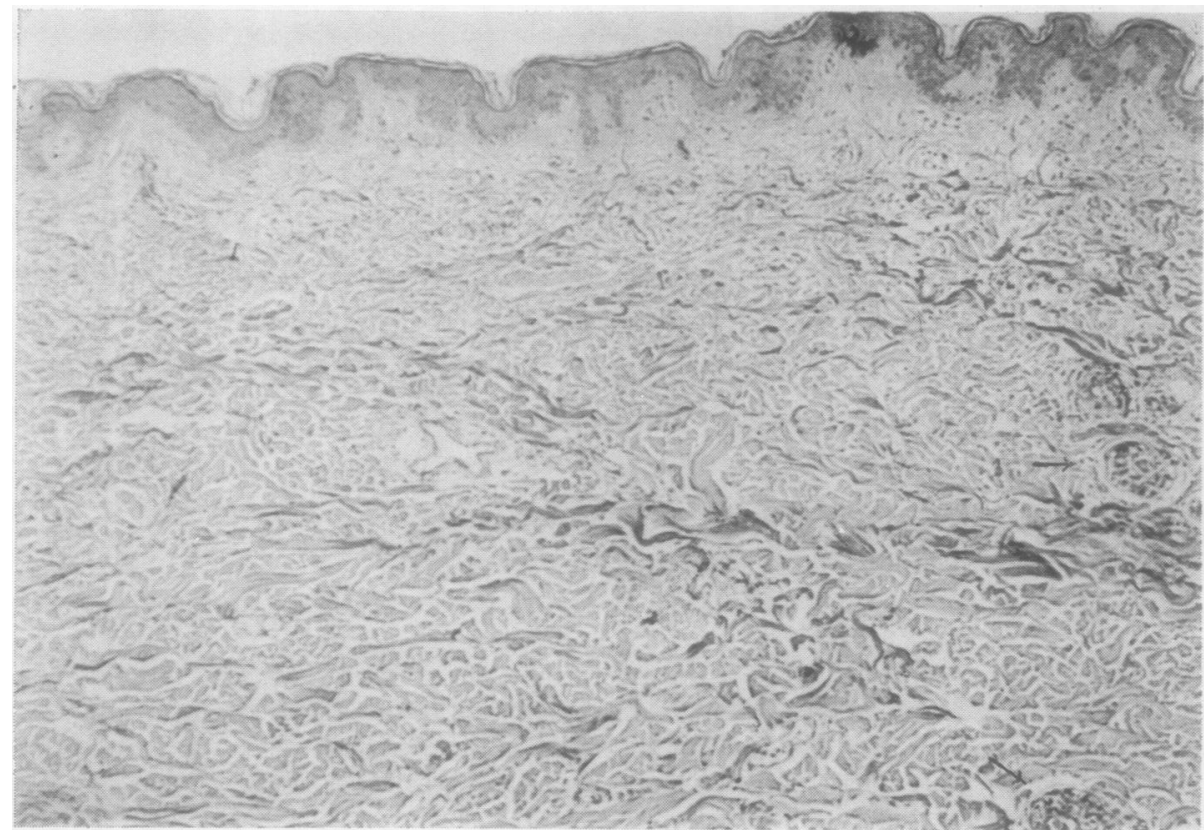

Fig 4 Scanning view depicting the scattered involvement (nests) of the entire dermal thickness.

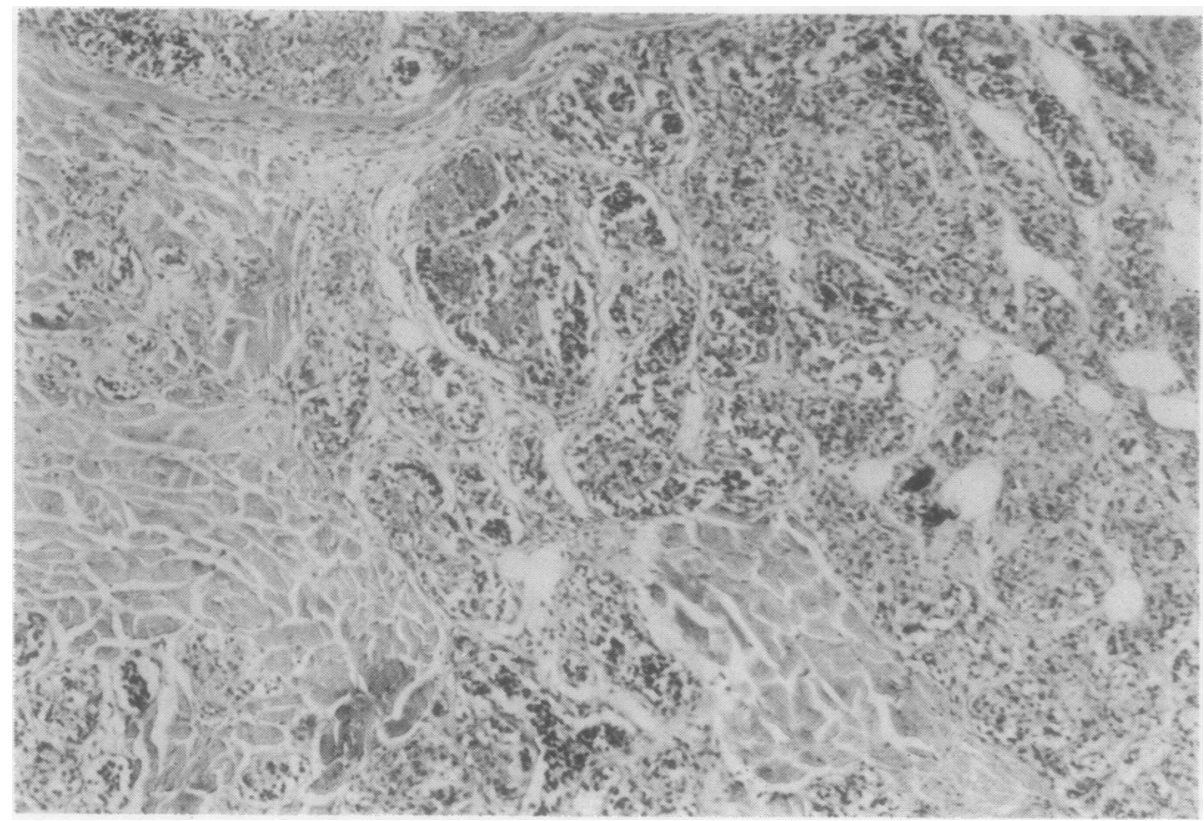

Fig 5 Nest-like involvement of lower dermal margin and subcutaneous tissue. 


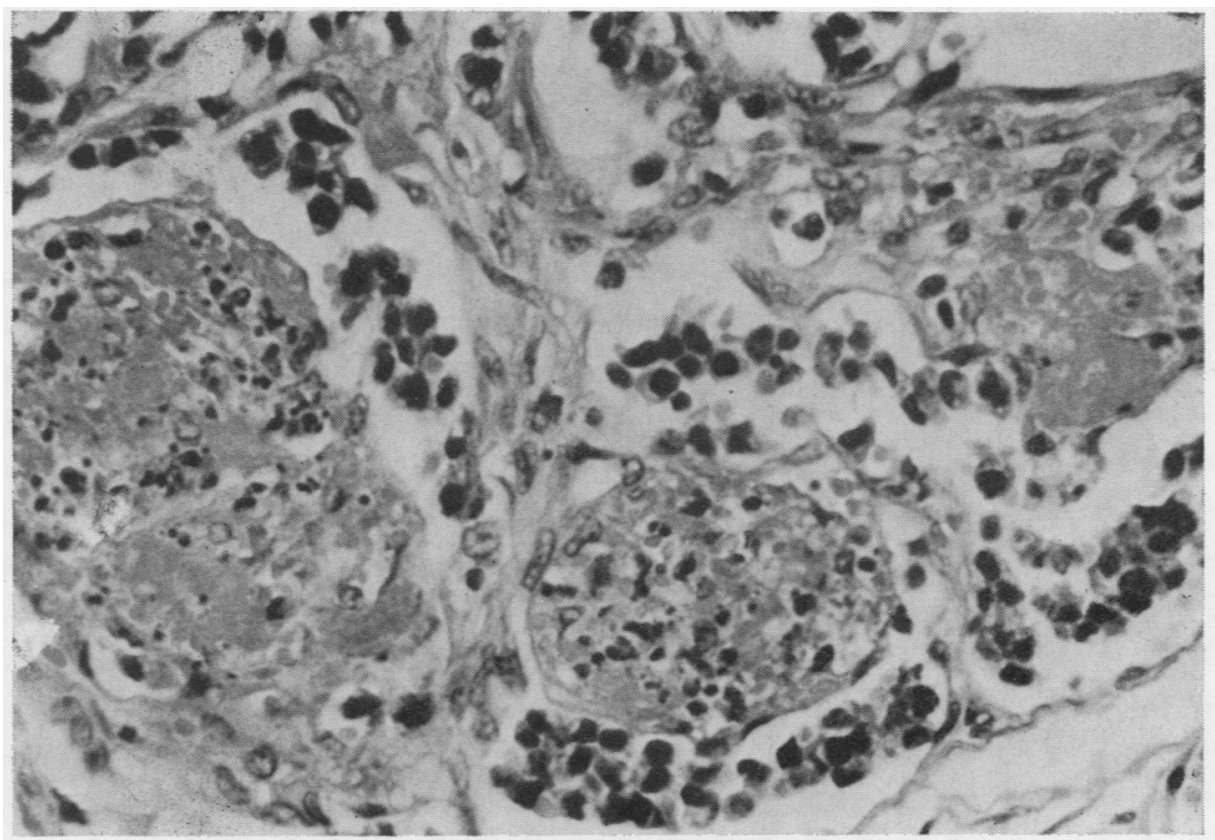

Fig 6 Note irregular and disorganized nesting of variably distorted capillary channels.

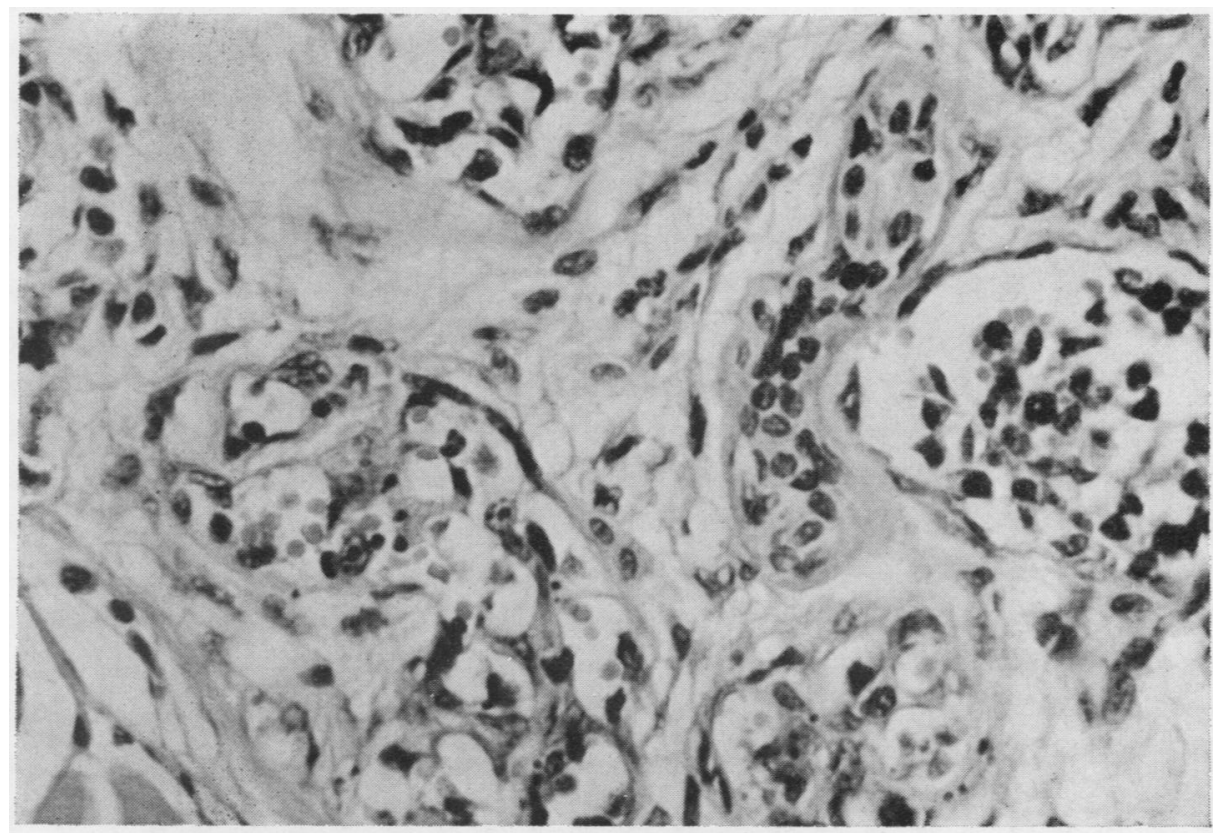

Fig 7 High magnification showing the shedding of disorganized and poorly adherent atypical endothelial cells into the vessel lumen with partially organized central thrombosis. 


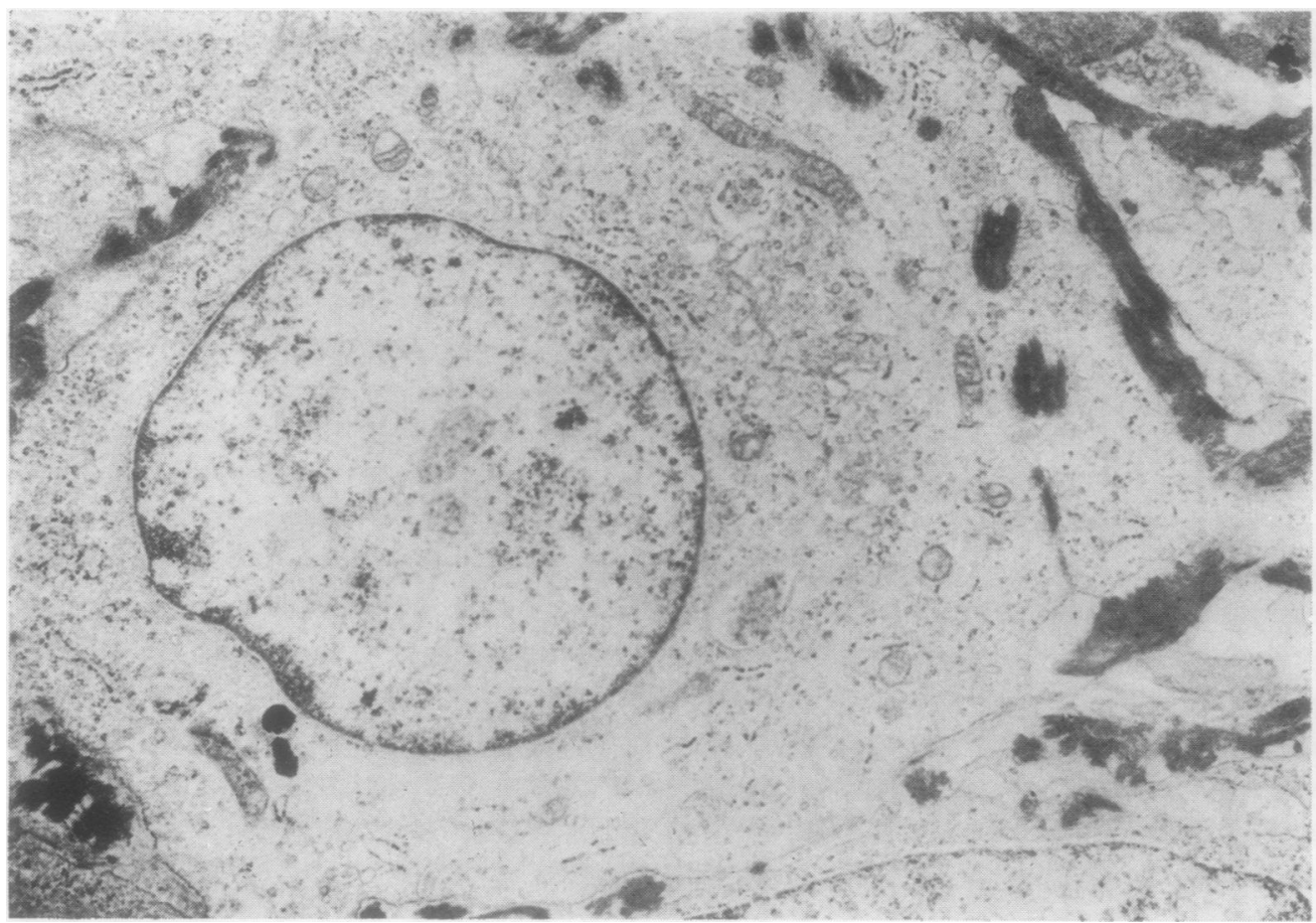

Fig 8

Figs 8 and 9 Electron photomicrographs of a cell consistent in type with that having a phagocytic endothelial cell origin.

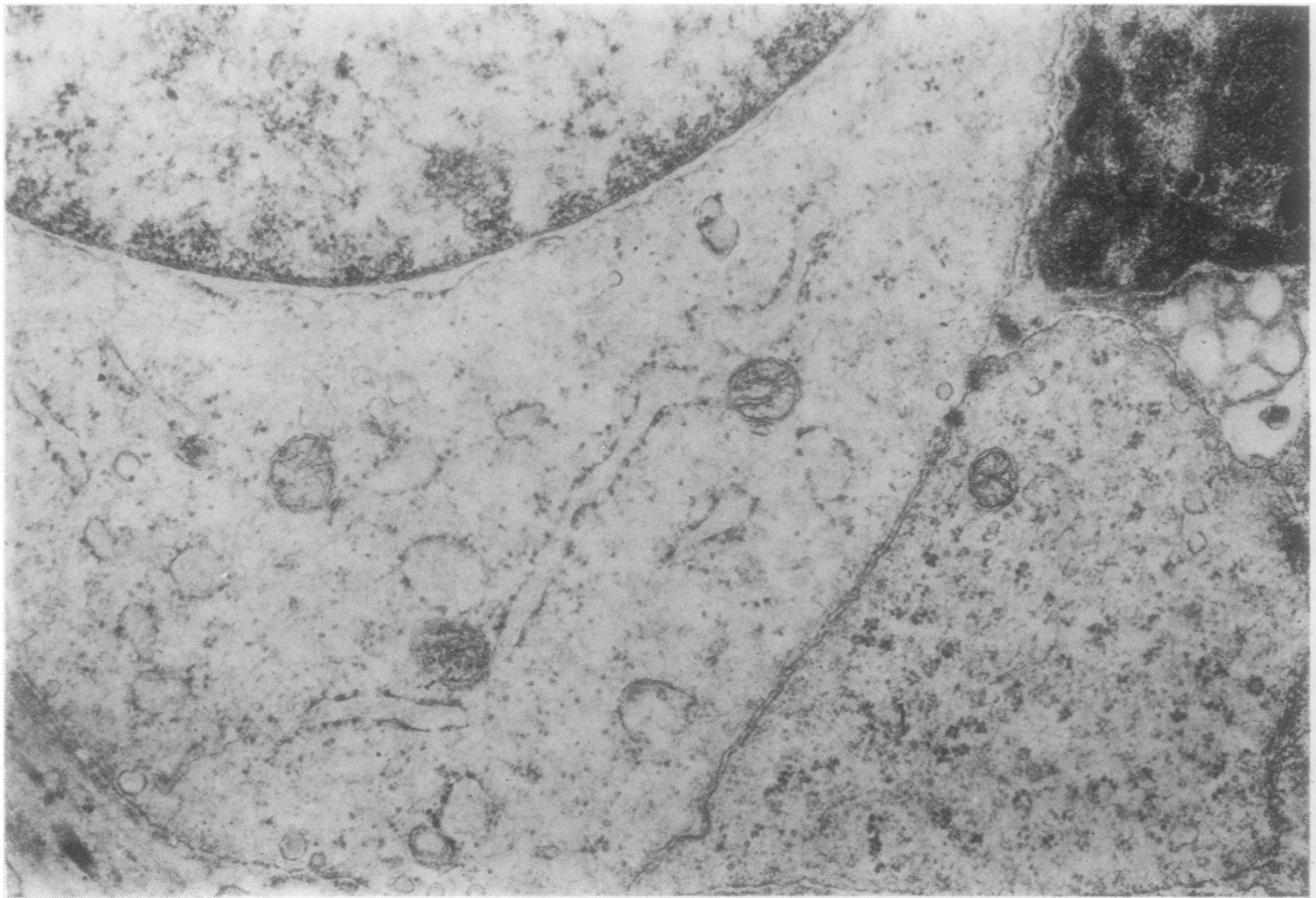

Fig 9 
overlying epidermis was uninvolved. A diagnosis of systemic endotheliomatosis was established ${ }^{1}$. Results of enzyme histochemistry which followed the expected endothelial cell pattern of activity are shown in the table. Electron microscopy showed proliferating intraluminal cells interpreted as consistent with cells of a phagocytic endothelial origin. No viruses or surface or cytoplasmic abnormalities were noted.

On 15 December 1970 isolated lesions were treated with radiotherapy using a superficial devise and a dosage of 300 rads per day for five days. The result was dramatic. The lesions seemed to 'melt' away, leaving only fibrotic markers. The patient was subsequently discharged on a chemotherapeutic regimen of $2 \mathrm{mg}$ intravenous vincristine weekly and $100 \mathrm{mg}$ cyclophosphamide by mouth three times daily.

The patient was then readmitted one week after discharge with a recurrent fever of $37 \cdot 2-38 \cdot 3^{\circ} \mathrm{C}$ $\left(99-101^{\circ} \mathrm{F}\right)$. The lesions showed no response to chemotherapy at this time. Over the subsequent week right sixth cranial nerve palsies developed, possibly as a complication of the vincristine therapy. An echoencephalogram, electroencephalogram, brain scan, and skull radiographs were reported as normal. Additional radiotherapeutic measures were planned but the patient developed massive haemoptyses and died on 23 February 1971.

A necropsy limited to the abdomen was done. The findings were systemic endotheliomatosis of the gastric mucosa, gastric wall, oesophagus, retroperitoneal fat, pancreatic interstitium, spleen, and left kidney. Only the soft, glistening, light grey, elevated $1.5 \mathrm{~cm}$ plaque-like gastric lesion was discernible grossly. The remaining sites were microscopic findings on random sections. These lesions had a morphology identical with the diagnostic biopsy specimens apart from perivascular tissue invasion which was not present on the biopsy section. Additional unrelated findings consisted of one superficial gastric ulcer $(2 \mathrm{~cm})$, two hepatic haemangiomas $(1 \mathrm{~cm}$ and $0.8 \mathrm{~cm})$, and one renal leiomyoma $(0 \cdot 8 \mathrm{~cm})$.

\section{Discussion}

The initial presentation of systemic endotheliomatosis might be divided into two general categories: the presence of (1) gross cutaneous lesions, or (2) vascular occlusive disease. The cutaneous manifestations in our patient parallel those reported by Braverman and Lerner (1961), Haber, Harris-Jones, and Wells (1964), Fievez, Fievez, and Hustin (1971), and Pfleger and Tappeiner (1959). These patients all had

'Slides reviewed by R. Rachman, MD, Einstein Medical Center, Philadelphia, Pa, and I. M. Braverman, MD, Yale University, New Haven, Conn. multiple cutaneous plaques suggestive of a neoplastic process of vascular origin. Not all cases have had cutaneous involvement. The two cases reported by Strouth, Donahue, Ross, and Aldred (1965) lacked skin lesions, and clinical manifestations were solely bizarre neurological signs and symptoms progressing to dementia. On microscopic examination these two cases had the same occlusive endothelial proliferation as our patient. The Latin American case reported by Abulafia et al (1969) developed ischaemic gangrene of the distal limbs secondary to this occlusive endothelial proliferation.

The natural history of systemic endotheliomatosis has tended toward rapid disease progression unabated by radiotherapy and chemotherapy followed by death within 15 months. Although the present case did display an impressive response of individual lesions to radiotherapy, the natural history of the disease process was unaffected. The only clear violation to this concept is the original case report of Pfleger and Tappeiner (1959). Corticosteroid therapy afforded their patient a temporary response, which was followed by a clinically benign course of exacerbations and remissions over a seven-year period. The patient was subsequently lost to follow-up. Both Tappeiner and Pfleger (1963) and Fievez et al (1971) have implicated the young age of the original patient (first involvement at age 24) as being the beneficial factor in the comparatively benign clinical course. This concept of age as a prognostic factor must await additional support.

Although the distinct morphological progression of the cutaneous lesions through the four stages previously described is not clearly presented elsewhere, Haber et al (1964) have suspected temporal changes in individual lesions, and Braverman and Lerner (1961) have noted the various morphological stages described at a single point in time.

Histologically this patient's lesions were identical with those of other case reports in the literature. Dr Braverman had the opportunity personally to review both our case and that of Haber et al (1964) and found the histopathology of both cases to be indistinguishable from that of his own. Intravascular proliferation of atypical endothelial cells has been common to all reported cases. Extravascular invasion was not noted by Haber et al (1964), but necropsy material was not available for extensive review. The ability of these atypical cells to invade categorizes this disease process as a malignant one. This point is commonly accepted in the literature with the exception of the report by Fievez et al (1971).

The spleen in our patient was involved. To our knowledge, this represents the first time the disease has definitely involved any of the so-called classic reticulosis sites (spleen, liver, lymph nodes). Lack of 
involvement at such sites had previously been considered to be a distinguishing characteristic of this pathological entity. The finding of splenic involvement now casts considerable doubt upon the validity of such a concept.

Since Pfleger and Tappeiner first described this disorder in 1959, diagnosis has rested solely in the histopathological examination of involved tissue. Evidence is now available to enter this entity in one's differential diagnosis based on clinical information. This entity has presented clinically as either a cutaneous disorder or a vascular occlusive syndrome. Furthermore, if the cutaneous lesions are present, the presence of various distinct morphological lesions and the progression of newly arisen lesions through the four morphological stages are a key to clinical diagnosis. This entity has also been shown to be truly systemic, possesses malignant characteristics, and carries a poor prognosis. These data must be kept in mind as an appropriate therapy for this disease is sought.

\section{References}

Abulafia, J., Ligorraga, S., Saliva, S., et al (1969). Angioendotheliomatosis proliferata sistematica (Pflegery-Tappeiner). Derm. ibero lat. amer., 11, 23-40.

Braverman, I. M. and Lerner, A. B. (1961). Diffuse malignant proliferation of vascular endothelium. Arch. Derm., 84, 22-30.

Fievez, M., Fievez, C., and Hustin, J. (1971). Proliferating systematized angioendotheliomatosis. Arch. Derm., 104, 320-324.

Haber, H., Harris-Jones, J. N., and Wells, A. L. (1964). Intravascular-endothelioma (endothelioma in situ, systemic endotheliomatosis). J. clin. Path., 17, 608-611.

Pfleger, L. and Tappeiner, J. (1959). Zu Kenntnis der systemisierten Endotheliomatose der cutanen Blutgefässe (reticuloendotheliose ?). Hautarzt., 10, 359-363.

Strouth, J. C., Donahue, S., Ross, A., and Aldred, A. (1965). Neoplastic angioendotheliomatosis. Neurology, 15, 644648.

Tappeiner, J. and Pfleger, L. (1963). Angioendotheliomatosis proliferans systemisata: ein klinisch und pathohistologisch neues Krankheitsbild. Hautarzt, 14, 67-70. 